\title{
Guanosine monophosphate synthase upregulation mediates cervical cancer progression by inhibiting the apoptosis of cervical cancer cells via the Stat3/P53 pathway
}

\author{
JUAN WANG $^{1 *}$, YUHONG WU $^{1 *}$, YAN LI $^{2 *}$, YAMEI WANG $^{1}$, FANGRONG SHEN $^{1}$, \\ JINHUA ZHOU $^{1}$ and YOUGUO CHEN ${ }^{1}$
}

${ }^{1}$ Department of Gynecology and Obstetrics, The First Affiliated Hospital of Soochow University, Suzhou, Jiangsu 215006;
${ }^{2}$ Department of Gynecology and Obstetrics, The First People's Hospital of Yancheng, Yancheng, Jiangsu 224000, P.R. China

Received June 17, 2020; Accepted January 18, 2021

DOI: $10.3892 /$ ijo.2021.5183

\begin{abstract}
Guanosine monophosphate synthase (GMPS) participates in chromatin and gene regulation in multiple types of organisms, and is highly expressed in a variety of human malignancies. The purpose of the present study was to explore the expression of GMPS and its role in cervical cancer (CC), and to provide ideas for improving the clinical efficacy of $\mathrm{CC}$ treatment. In the present study, immunohistochemistry, reverse transcription-quantitative PCR analysis, Cell Counting Kit-8 assay, 5-ethynyl-2'-deoxyuridine assay, flow cytometry, western blotting and immunofluorescence assays were conducted to detect the expression of GMPS in normal cervical tissues, $\mathrm{CC}$ tissues, para-cancerous tissues and $\mathrm{CC}$ cell lines. Moreover, the present study detected the effect of GMPS knockdown on CC cell proliferation, clonal formation ability, aging and apoptosis, as well as on the expression levels of apoptosis-related proteins in tumor cells. The present results demonstrated that the expression level of GMPS in CC was significantly higher compared with that of adjacent tissues; the expression rate of GMPS in CC was 57.36\%. GMPS expression was found to successively and gradually increase from that in normal cervical tissues, to that in cervical intraepithelial neoplasia and CC tissues. The abnormal expression of GMPS was positively associated with the degree of CC differentiation and the depth of early invasion. Small interfering (si) RNA knockdown of GMPS inhibited proliferation and colony
\end{abstract}

Correspondence to: Dr Jinhua Zhou or Professor Youguo Chen, Department of Gynecology and Obstetrics, The First Affiliated Hospital of Soochow University, 899 Pinghai Road, Suzhou, Jiangsu 215006, P.R. China

E-mail: jsjhzh@126.com

E-mail: chenyouguo@suda.edu.cn

*Contributed equally

Key words: guanosine monophosphate synthase, cervical cancer, proliferation, senescence, apoptosis formation, and promoted aging and apoptosis of CC cells. Furthermore, subcutaneous injection of GMPS-knockdown tumor cells in nude mice resulted in a decrease in the proliferative ability of the tumor. The animal experimental results showed that the tumor growth rate of the short hairpin (sh) RNA-GMPS group was significantly slower than that of the HeLa sh-negative control group. It was identified that GMPS may inhibit CC cell senescence and apoptosis via the Stat3/P53 molecular pathway. Collectively, the present results suggested that GMPS may be a marker of unfavorable prognosis of $\mathrm{CC}$, and it may also be a potential therapeutic target for CC.

\section{Introduction}

Cervical cancer (CC) is one of the most common malignant types of tumors in the female reproductive system, and poses a major threat to the physical and mental health of women (1). According to the World Health Organization, there are $\sim 530,000$ new cases of $\mathrm{CC}$ each year, with an annual number of CC fatalities of $26,000,90 \%$ of which are from developing countries $(2,3)$. The 5-year survival rate for early-stage $\mathrm{CC}$ is $91.5 \%$, while for patients with advanced-stage $\mathrm{CC}$ it is only $16.5 \%(4,5)$. The main treatments for advanced CC include radiation therapy and chemotherapy (6). Moreover, progress has been achieved in understanding the molecular mechanism in $\mathrm{CC}$ and novel therapeutic strategies are emerging. For instance, targeting therapeutic molecules enhances the sensitivity of CC to radiotherapy and chemotherapy (7).

The guanosine monophosphate synthase (GMPS) gene is located on chromosome $3 \mathrm{q} 24$, GMPS is involved in the guanine nucleotide synthesis process and converts xanthine 5'-monophosphate to guanine monophosphate (8). In addition to its classic functions in GMP synthesis, GMPS has also been reported to be involved in chromatin and gene regulation in fruit flies. It has been found that GMPS/ubiquitin-specific protease 7 binds to ecdysone-regulated loci and mutants displays severe misregulation of ecdysone target genes $(9,10)$. GMPS is upregulated in numerous malignant tumors, such as lung squamous cell carcinoma, ovarian serous cystadenocarcinoma and head and neck squamous cell carcinoma (11-13). A previous study revealed that GMPS participates in radiotherapy 
resistance and plays a role in inducing cell apoptosis of nasopharyngeal carcinoma (12). It has been reported that the expression of GMPS strongly affects the invasive capacity of melanoma cells and ultimately tumor growth, and angustmycin A, a nucleoside-analog inhibitor of GMPS produced by Streptomyces hygroscopicus efficiently suppresses melanoma cell invasion in vitro and tumorigenicity in immunocompromised mice (14).

To the best of our knowledge, there have been no studies reporting the biological role of GMPS in CC. Therefore, the present study aimed to investigate the expression of GMPS in $\mathrm{CC}$ and to elucidate its effects on the proliferation, aging and apoptosis of CC cells.

\section{Materials and methods}

Subjects. The enrolled subjects included patients with cervical intraepithelial neoplasia (CIN) and CC. Patients were diagnosed and treated at the Department of Gynecology of The First Affiliated Hospital of Soochow University (Suzhou, China) between January 2019 and June 2020. In this study, patients with other malignant tumors or history of treatment for other malignant tumors were excluded. The clinical and pathological data were collected. Patients with other benign tumors who underwent total hysterectomy were assigned as controls. The cervical pathological diagnosis was normal in the controls. Written informed consent was obtained from all patients, and the study was approved by the Ethics Committee of The First Affiliated Hospital of Soochow University (approval no. 2020LS265).

Bioinformatics analysis. GMPS gene expression was analyzed using microarray gene expression data from the Oncomine database (http://www.oncomine.org). Based on the Multi-cancer Statistics by Pyeon et al (15), Cervix Statistics by Biewenga et al (16), Cervix 2 Statistics by Scotto et al (17) and Cervix Statistics by Zhai et al (18), the four datasets were evaluated via bioinformatics analysis. The differential expression of GMPS was determined between $\mathrm{CC}$, which was obtained from the database by defining the type of cancer as $\mathrm{CC}$, and normal cervical tissues. The data type was 'mRNA', and the type of analysis was based on filtering results of cancer vs. normal cervix. The Oncomine algorithm was selected for comparative statistical analysis.

Immunohistochemistry (IHC). The specimen was fixed with $10 \%$ formalin at room temperature for $24 \mathrm{~h}$, dehydrated using gradient ethanol and embedded into paraffin blocks. Paraffin-embedded specimens were cut on a microtome at a thickness of $4 \mu \mathrm{m}$ and baked in an oven at $60^{\circ} \mathrm{C}$ for $30 \mathrm{~min}$. After the tissue sections were routinely dewaxed and rehydrated, the sections were washed with PBS solution. The sections were immersed in $0.01 \mathrm{M}$ citrate buffer solution ( $\mathrm{pH}$ 6.0). Following incubation for $3 \mathrm{~min}$, sections were removed and cooled. Endogenous peroxidase activity was blocked by adding one drop of peroxidase blocking agent, and sections were washed again with PBS solution. Subsequently, appropriately diluted GMPS antibody (anti-GMP synthase antibody-C-terminal; cat. no. ab135538; 1:100; Abcam) was added at $\sim 50 \mu 1$. The specimens were incubated overnight in a wet box at $4^{\circ} \mathrm{C}$ in a refrigerator. Sections were removed the next day, washed with PBS and incubated with $50 \mu 1$ secondary antibody reagent (cat. no. GK600711; 1:100; Shanghai South Gene Technology Co., Ltd.). Sections were washed with PBS, stained with brown glucose oxidase-DAB and then incubated with hematoxylin solution. Following dehydration with anhydrous ethanol, the slide was sealed with neutral resin. All these procedures were conducted at room temperature for $30 \mathrm{~min}$. The slides were observed under a light microscope. The IHC results were interpreted by combining the staining intensity of the positive reaction cells and the staining area.

Cellular staining intensity and cell staining area were independently assessed by two pathologists, without prior knowledge of patient information. The positive reaction cells were defined as those with brown-yellow cytoplasmic staining. According to the intensity, staining was defined as: i) Negative (0); ii) mild positive (1); iii) intermediate positive (2); and iv) strong positive (3). According to the percentage of positive cells, scoring was as follows: i) $<5 \%$ (0); ii) $5-25 \%$ (1); iii) $26-50 \%$ (2); iv) $51-75 \%$ (3); and v) $>75 \%$ (4). Under low magnification, five fields of view were randomly selected to determine the results. The overall score was comprehensively evaluated using the staining range and intensity. Counting cells required a clear structure, good positioning and a light background. When the staining was heterogeneous, sections were independently scored and the results were comprehensively evaluated. For example, a specimen containing $75 \%$ of tumor cells with moderate intensity staining (total score: $3 \times 2=6$ ), with the remaining $25 \%$ of tumor cells exhibiting mild intensity staining (total score: $1 \times 1=1$ ), the final score would be $7(6+1=7)$. The staining index $(0-12)$ was determined from the staining intensity score and the stained area score. Scores in the range of 0-7 were defined as low expression, and 8-12 as high expression.

Cell lines and small interfering (si)RNA. Human CC cell lines (HeLa, SiHa, CaSki and C33A) were purchased from The Cell Bank of Type Culture Collection of The Chinese Academy of Sciences. SiHa, C33A and CaSki cells were cultured with RPMI-1640 medium (HyClone; Cytiva) containing 10\% FBS (Biosera) and 1\% penicillin-streptomycin (Beyotime Institute of Biotechnology). HeLa cells were cultured with $10 \%$ FBS and $1 \%$ penicillin-streptomycin in DMEM (HyClone; Cytiva). HeLa, SiHa, CaSki and C33A cells grown on a 6-well plate (30-50\% confluence) were transfected with siRNA (100 nM per well) using Lipofectamine ${ }^{\circledR} 3000$ (Invitrogen; Thermo Fisher Scientific, Inc.) according to the manufacturer's protocols. Transfected cells were incubated at $37^{\circ} \mathrm{C}$ and $5 \% \mathrm{CO}^{2}$ for 2-4 days for subsequent experiments. The chemically synthesized GMPS specific double-stranded siRNA targeting sequences were as follows: Control (Ctrl) siRNA sense, 5'-UGG UUUACAUGUCGACUAATT-3' and antisense, 5'-UUAGUC GACAUGUAAACCATT-3'; siRNA\#1 sense, 5'-GCAUGUGUC ACAACGUUAACA-3' and antisense, 5'-UUAACGUUGUGA CACAUGCGA-3'; siRNA\#2 sense, 5'-CGAAUUAUGUAUGA CUUAACA-3' and antisense, 5'-UUAAGUCAUACAUAAUUC GAG-3'; and siRNA\#3 sense, 5'-UGGAGAUAGUGUAGACAA AGU-3' and antisense, 5'-UUUGUCUACACUAUCUCCAUG-3'. The siRNAs were synthesized by Shanghai Integrated Biotech Solutions Co., Ltd. 
Western blotting. Total protein was extracted from the cells with RIPA lysis buffer (Beyotime Institute of Biotechnology) after transfection for $72 \mathrm{~h}$ and the concentration of the protein was determined with a Pierce ${ }^{\mathrm{TM}}$ BCA Protein assay kit (Peirce; Thermo Fisher Scientific, Inc.). Protein samples (15-30 $\mu \mathrm{g} /$ lane) were separated via 10\% SDS-PAGE, and then separated proteins were transferred to PVDF membranes (EMD Millipore). The membranes were blocked with 5\% BSA (Guangzhou Saiguo Biotech Co., Ltd.) for $1 \mathrm{~h}$ at room temperature. Subsequently, primary antibodies were added and incubated overnight at $4^{\circ} \mathrm{C}$. Following washes with TBS with $0.05 \%$ Tween-20, the membranes were incubated with a secondary antibody [anti-mouse (cat. no. A0216) and anti-rabbit (cat. no. A0208) $\operatorname{IgG}(\mathrm{H}+\mathrm{L})$ antibodies; 1:1,000; Beyotime Institute of Biotechnology] for $1 \mathrm{~h}$ at room temperature. Protein bands were visualized using an ECL kit (Shanghai Yeasen Biotechnology Co., Ltd.). The following primary antibodies were used: Anti-GMPS (1:1,000; cat. no. 14602; Cell Signaling Technology, Inc.), anti-P53 (1:1,000; cat. no. 2527; Cell Signaling Technology, Inc.), anti-phosphorylated (p)-P53 (1:1,000; cat. no. 2521; Cell Signaling Technology, Inc.), anti-Stat3 (1:1,000; cat. no. 9139; Cell Signaling Technology, Inc.), anti-p-Stat3 (1:1,000; cat. no. 9145; Cell Signaling Technology, Inc.) and anti-GAPDH (1:2,000; cat. no. 97166; Cell Signaling Technology, Inc.).

Reverse transcription-quantitative $(R T-q) P C R$ analysis. Tissue samples and total RNA from CC cell lines transfected for 48 $\mathrm{h}$ were extracted with TRIzol (Invitrogen; Thermo Fisher Scientific, Inc.) and reverse transcription was performed using PrimeScript $^{\mathrm{TM}}$ RT Reagent Kit with gDNA Eraser (cat. no. RR047A; Takara Bio, Inc.) according to the manufacturer's protocol. RT-qPCR was performed with SYBR-Green reagent (Takara Bio, Inc.). The expression levels of GMPS in CC tissues, paired adjacent cancer tissues and four CC cell lines were analyzed using the $2^{-\Delta \Delta C q}$ method (19). $\beta$-actin was used as an internal reference. The reverse-transcribed cDNA was used as a template. The primer sequences used were as follows: GMPS forward, 5'-ATGGCTCTGTGCAACGGAG-3' and reverse, 5'-CCTCACTCTTCGGTCTATGACT-3'; and $\beta$-actin forward, 5'- TGACGTGGACATCCGCAAAG-3' and reverse, 5'-CTGGAAGGTGGACAGCGAGG-3'. The thermocycling conditions were as follows: Initial denaturation at $95^{\circ} \mathrm{C}$ for $30 \mathrm{sec}$, followed by 40 cycles of denaturation at $95^{\circ} \mathrm{C}$ for $5 \mathrm{sec}$ and annealing at $60^{\circ} \mathrm{C}$ for $30 \mathrm{sec}$. Analysis of the dissolution stage curve was performed under the following conditions: $95^{\circ} \mathrm{C}$ for $15 \mathrm{sec}, 60^{\circ} \mathrm{C}$ for $1 \mathrm{~min}, 95^{\circ} \mathrm{C}$ for $30 \mathrm{sec}$ and $60^{\circ} \mathrm{C}$ for $15 \mathrm{sec}$.

Cell Counting Kit-8 (CCK-8) assay. There were three groups in this CC cell line experiment: i) Ctrl, siRNA negative control; ii) siRNA\#1 transfection; and iii) siRNA\#2 transfection. In total, three repeat wells were used in each group. Cells were incubated for $1 \mathrm{~h}$ with CCK-8 (New Cell \& Molecular Biotech Co., Ltd.). The absorbance at $450 \mathrm{~nm}$ was detected with a microplate reader at 24, 48, 72, 96 and $120 \mathrm{~h}$ after transfection. The cell growth curve was created after zeroing the blank control group.

5-Ethynyl-2'-deoxyuridine (EdU) assay for cell proliferation. There were two groups in this $\mathrm{CC}$ cell line experiment: i) Ctrl, siRNA negative control; and ii) siRNA\#1 transfection. In total, three repeat wells were used in each group. At $72 \mathrm{~h}$ after cell transfection, $500 \mu \mathrm{l}$ EdU medium $(50 \mu \mathrm{M}$; Beyotime Institute of Biotechnology) was added to each well and cells were incubated for $2 \mathrm{~h}$. Then, the cells were fixed with $4 \%$ paraformaldehyde for $15 \mathrm{~min}$ at room temperature and permeated. A total of $200 \mu \mathrm{l}$ Click working solution was added to each well and incubated for $30 \mathrm{~min}$. Cell nuclei were stained with Hoechst for $10 \mathrm{~min}$ at room temperature, and imaged with a fluorescence microscope (magnification, $\mathrm{x} 100)$.

Clone formation assay to assess cell proliferation. There were three experimental groups of CC cell lines for this assay: i) Ctrl, siRNA negative control; ii) siRNA\#1 transfection; and iii) siRNA\#1 transfection combined with cisplatin $(3 \mu \mathrm{g} / \mathrm{ml}$; Qilu Pharmaceutical Co., Ltd.). At 48 h after transfection, 500 cells per well were added; three wells were used in each group. The cells were stained with crystal violet solution for $30 \mathrm{~min}$ and observed under an inverted microscope (CKX31SF; Olympus Corporation) at x100 magnification 7-10 days later. The cell clones with $>50$ cells were counted as one monoclone, and the mean number of clones on the plate was used to calculate the cell clone-forming ability.

Flow cytometry for analysis of apoptosis. There were three experimental groups of CC cell lines for this analysis: i) Ctrl, siRNA negative control; ii) siRNA\#1 transfection; and iii) siRNA\#2 transfection. HeLa, C33A, SiHa and CaSki cells in the logarithmic growth phase were collected and added to 6-well plates, and then transfected with siRNA at 30-50\% confluence. Cells were digested and the transient transfection was terminated after $72 \mathrm{~h}$ to create a single-cell suspension. Cells were centrifuged at $500 \mathrm{x} \mathrm{g}$ for $5 \mathrm{~min}$, and washed twice with PBS. Then, $100 \mu 1$ Annexin V-FITC binding solution (BD Biosciences) was added to re-suspend the cells. After adding $5 \mu \mathrm{l}$ PE-Annexin $\mathrm{V}$ and $5 \mu \mathrm{l}$ 7-AAD staining solution, cells were incubated at room temperature for $15 \mathrm{~min}$ in the dark. Then, $400 \mu \mathrm{l}$ Annexin V-FITC was added and the cells were detected with a FC 500 flow cytometer (Beckman Coulter, Inc.). The results were analyzed using FlowJo v10 software (FlowJo LLC) to create a scatter plot. The living cells were on the lower left quadrant (FITC/7-AAD ${ }^{-}$), early apoptotic cells on the lower right quadrant and late apoptotic and dead cells on the upper right quadrant.

$\beta$-galactosidase staining for cell senescence. HeLa and $\mathrm{SiHa}$ cells were selected for $\beta$-galactosidase staining. Cells were divided into two groups: i) Ctrl, siRNA negative control; and ii) siRNA\#1 transfection. A cell senescence $\beta$-galactosidase staining kit (Jiangsu Biyuntian Biotechnology Research Institute) was used for staining and fixing. Cells were cultured in a 6-well plate and transfected at $30-50 \%$ confluence. Each group of cells was collected, washed once with PBS, incubated with $\beta$-galactosidase staining fixative and fixed at room temperature for $15 \mathrm{~min}$. After aspirating the fixative, washing with PBS three times and adding $1 \mathrm{ml}$ staining solution to each well, the cells were incubated at $37^{\circ} \mathrm{C}$ overnight. The results were observed and images were captured under an inverted microscope (magnification, x100). 
Immunofluorescence staining. There were two experimental groups of HeLa and SiHa cells in this part of the study: i) Ctrl, siRNA negative control; and ii) siRNA\#1 transfection. CC cells were seeded at a density of 5x104/well in a 24-well cell plate with small glass slides. Cells were transfected with siRNA for $48 \mathrm{~h}$, according to their experimental groups. Cells were washed three times with pre-chilled PBS and fixed with paraformaldehyde (4\%) for $15 \mathrm{~min}$ at room temperature. Cells were washed twice with ice-cold PBS, incubated with $0.5 \%$ Triton for $10 \mathrm{~min}$, washed twice with PBS and blocked with 5\% BSA (Guangzhou Saiguo Biotech Co., Ltd.) in PBS at room temperature for $1 \mathrm{~h}$. Cells were removed from the small round glass and inverted onto the parafilm, which was coated with the primary antibodies (1:100; cat. nos. 2521 and 9145; Cell Signaling Technology, Inc.). After incubation overnight at $4^{\circ} \mathrm{C}$, the slide was removed and placed in a 12-well plate. After being washed with PBS, the small round glass was removed and the plate was incubated with a secondary antibody (cat. no. A0423; 1:500; Beyotime Institute of Biotechnology) at room temperature for $1 \mathrm{~h}$. The washing steps were the same as aforementioned. The nuclei were stained with DAPI solution in the dark for $30 \mathrm{~min}$. Under the same condition in the dark, the small round glass slide was inverted, placed on a glass slide and an anti-fluorescent quencher was added dropwise. The slides were observed and imaged using a fluorescence microscope (magnification, x200).

Animal experiments. A total of 12 female athymic BALB/c nude mice (age, 4-5 weeks; weight, 16-18 g) were obtained from the Model Animal Research Center of Soochow University (Suzhou, China). The mice were housed in specific pathogen-free barrier facilities in a temperature-controlled room $\left(24^{\circ} \mathrm{C}\right)$ with a $12 \mathrm{~h}$ light/dark cycle and $35-40 \%$ relative humidity, and were permitted free access to food and drinking water. The body weight of each mouse was measured every 2 days. The mice were humanely sacrificed via cervical dislocation at the study endpoint. All experiments were performed in accordance with the Guide for the Care and Use of Laboratory Animals (NIH publication 80-23, revised 1996) (20), with the approval of the Ethics Committee of Soochow University (approval no. SUDA20201027A01).

To obtain stable cell lines, lentivirus supernatant of sh-GMPS and sh-control (GeneChem, Inc.) were added to HeLa cells at MOI 10, according to the manufacturer's instructions, and incubated at $37^{\circ} \mathrm{C}$ and $5 \% \mathrm{CO}_{2}$ for $48 \mathrm{~h}$, followed by screening with $4 \mu \mathrm{g} / \mathrm{ml}$ puromycin for 2 weeks. Control HeLa cells and GMPS-knockdown HeLa cells $\left(2 \times 10^{6}\right.$ cells) were suspended in $100 \mu \mathrm{l}$ PBS media and were subcutaneously inoculated into the flanks of the mice. There were six mice in each group (control and sh-GMPS). Mice were monitored every 2 days for tumor growth, and tumor size was measured using a caliper. The tumor volume was calculated using the modified ellipsoid formula: Volume $=1 / 2 \times\left(\right.$ length $\times$ width $\left.{ }^{2}\right)$. After 5 weeks, the mice were sacrificed and tumor weight was measured. The maximum volume of the tumors was $1.17 \mathrm{~cm}^{3}$, and the maximum diameter of the tumors was $1.21 \mathrm{~cm}$. A section of each tumor tissue was fixed in $10 \%$ formalin at room temperature for $24 \mathrm{~h}$, and used for IHC. The remaining tumor tissues were used for protein and mRNA expression analyses, and the experiment methods were the same as above.
Statistical analysis. The data are presented as the mean \pm standard deviation. The clinical data are presented as percentages and statistical analysis was performed using Pearson Chi-square and Fisher's exact probability method. Each experiment was repeated $\geq 3$ times independently. The $\chi^{2}$ segmentation method or Fisher's exact probability method was used to further compare the two sample frequencies. The differences between two groups were examined using an unpaired Student's t-test and a one-way analysis of variance for normally distributed data, and using the Mann-Whitney U test for non-normally distributed data. SNK and Dunnett's post hoc tests were performed following ANOVA. P $<0.05$ (two-sided) was considered to indicate a statistically significant difference. All data analysis was performed using SPSS 22.0 software (IBM Corp.).

\section{Results}

Clinical characteristics of the patients. The median age of the patients was 51 years (age range, 25-76 years). There were 20 cases of normal cervical tissues, 11 cases with Grade CIN I, 16 cases with Grade CIN II, 22 cases with Grade CIN III and 129 cases with CC. A total of 198 patient specimens were collected in this study (among which, paired cancer and adjacent tissues were obtained from 32 cases). The histopathological types of CC included squamous cell carcinoma $(n=88)$, adenocarcinoma $(n=31)$, adenosquamous carcinoma $(n=6)$ and other special types $(n=4)$. Clinical staging of $\mathrm{CC}$ was based on International Federation of Gynecology and Obstetrics (FIGO 2014) staging criteria (21). There were 101 cases of early-stage CC (stage Ia $n=8$, stage Ib1 n=37, stage Ib2 n=29 and stage IIa $n=27)$. In total, 28 cases were at an advanced stage ( 5 cases of stage IIb, 15 cases of stage III and 8 cases of stage IV) (Tables I and II).

Bioinformatics analysis of the abnormal expression of GMPS in $C C$. In order to elucidate the association between GMPS and $\mathrm{CC}$, the differential expression of GMPS mRNA in CC tissue and normal cervical tissue was determined by analyzing the Oncomine microarray gene expression dataset. The results demonstrated that the expression of GMPS in CC tissues was significantly higher compared with that in the corresponding normal cervical tissues (Fig. 1A).

GMPS expression gradually increases from normal cervical to CIN to CC tissues. To verify the abnormal expression of the GMPS gene during the progression of $\mathrm{CC}$, IHC experiments were conducted in normal cervical, CIN I, CIN II, CIN III and CC tissues. During the progression through different stages of cancer, the expression rate of GMPS exhibited a significant increasing trend (Table I; Fig. $1 \mathrm{~B}$ and $\mathrm{C})$. Among them, the high expression rate was $0.00 \%(0 / 10), 9.09 \%(1 / 11), 18.75 \%(3 / 16), 36.36 \%(8 / 22)$ and $57.36 \%$ (74/129) in normal cervical, CIN I, CIN II, CIN III and $\mathrm{CC}$ tissues, respectively.

In $\mathrm{CC}$, there were 88 cases of squamous cell carcinoma, 31 cases of adenocarcinoma, 6 cases of adenosquamous carcinoma and 4 cases of other special types. The IHC results demonstrated that the high GMPS expression rate was $57.36 \%$ (74/129) in the CC cases (Table II; Fig. 2A and B). 
Table I. GMPS expression as determined via immunohistochemistry increased with the cervical histological grading.

\begin{tabular}{lccc}
\hline & & \multicolumn{2}{c}{ GMPS expression, \% $(\mathrm{n})$} \\
\cline { 3 - 4 } Histopathological diagnosis & $\mathrm{n}$ & Low & High \\
\hline Normal & 20 & $20(100.00)$ & $0(0.00)$ \\
CINI & 11 & $10(90.91)$ & $1(9.09)$ \\
CINII & 16 & $13(81.25)$ & $3(18.75)$ \\
CINIII & 22 & $14(63.64)$ & $8(36.36)$ \\
CC & 129 & $55(42.64)$ & $74(57.36)$ \\
\hline
\end{tabular}

GMPS, guanosine monophosphate synthase; CC, cervical cancer; CIN, cervical intraepithelial neoplasia.

Table II. Association between GMPS expression, assessed by immunohistochemistry, and clinicopathological parameters in patients with cervical cancer.

\begin{tabular}{|c|c|c|c|c|}
\hline \multirow[b]{2}{*}{ Clinical parameters } & \multirow[b]{2}{*}{$\mathrm{n}$} & \multicolumn{2}{|c|}{ GMPS expression, \% (n) } & \multirow[b]{2}{*}{ P-value } \\
\hline & & Low & High & \\
\hline Age, years & & & & 1.0000 \\
\hline$\leq 50$ & 70 & $30(42.86)$ & $40(57.14)$ & \\
\hline$>50$ & 59 & $25(42.37)$ & $34(57.63)$ & \\
\hline Serum SCCA & & & & 0.1711 \\
\hline$\leq 5$ & 72 & $25(34.72)$ & $47(65.28)$ & \\
\hline$>5$ & 44 & $25(56.82)$ & $19(43.18)$ & \\
\hline Unknown & 13 & $5(38.46)$ & $8(61.54)$ & \\
\hline FIGO staging & & & & 0.0661 \\
\hline Ia & 8 & $6(75.00)$ & $2(25.00)$ & \\
\hline Ib1 & 37 & $22(59.46)$ & $15(40.54)$ & \\
\hline $\mathrm{Ib} 2$ & 29 & 7 (24.14) & $22(75.86)$ & \\
\hline IIa & 27 & $9(33.33)$ & $18(66.67)$ & \\
\hline $\mathrm{IIb}$ & 5 & $2(40.00)$ & $3(60.00)$ & \\
\hline III & 15 & $6(40.00)$ & $9(60.00)$ & \\
\hline IV & 8 & $3(37.50)$ & $5(62.50)$ & \\
\hline Pathological type & & & & 0.7029 \\
\hline Squamous cell carcinoma & 88 & $38(43.18)$ & $50(56.82)$ & \\
\hline Adenocarcinoma & 31 & $12(38.71)$ & $19(61.29)$ & \\
\hline Adenosquamous carcinoma & 6 & $2(33.33)$ & $4(66.67)$ & \\
\hline Others & 4 & $3(75.00)$ & $1(25.00)$ & \\
\hline \multicolumn{5}{|l|}{ Early tumor metastasis } \\
\hline Stage Ib Yes & 31 & $15(48.39)$ & $16(51.61)$ & 0.6202 \\
\hline Stage Ib No & 35 & $14(40.00)$ & $21(60.00)$ & \\
\hline Stage IIa Yes & 11 & $5(45.45)$ & $6(54.55)$ & 0.4105 \\
\hline Stage IIa No & 16 & $4(25.00)$ & $12(75.00)$ & \\
\hline Tumor differentiation & & & & $<0.0001^{\mathrm{a}}$ \\
\hline Low-to-medium & 86 & $25(29.07)$ & $61(70.93)$ & \\
\hline High & 43 & $30(69.77)$ & $13(30.23)$ & \\
\hline \multicolumn{5}{|l|}{ Early infiltration depth } \\
\hline Stage Ib deep muscular layer & 28 & $7(25.00)$ & $21(75.00)$ & $0.0118^{\mathrm{a}}$ \\
\hline Stage Ib superficial layer & 38 & $22(57.89)$ & $16(42.11)$ & \\
\hline Stage IIa deep muscular layer & 19 & $5(26.32)$ & $14(73.68)$ & 0.1972 \\
\hline Stage IIa superficial layer & 8 & $4(50.00)$ & $4(50.00)$ & \\
\hline
\end{tabular}

${ }^{a} \mathrm{P}<0.05$. GMPS, guanine monophosphate synthase; SCCA, squamous cell carcinoma antigen; FIGO staging, International Federation of Gynecology and Obstetrics. 

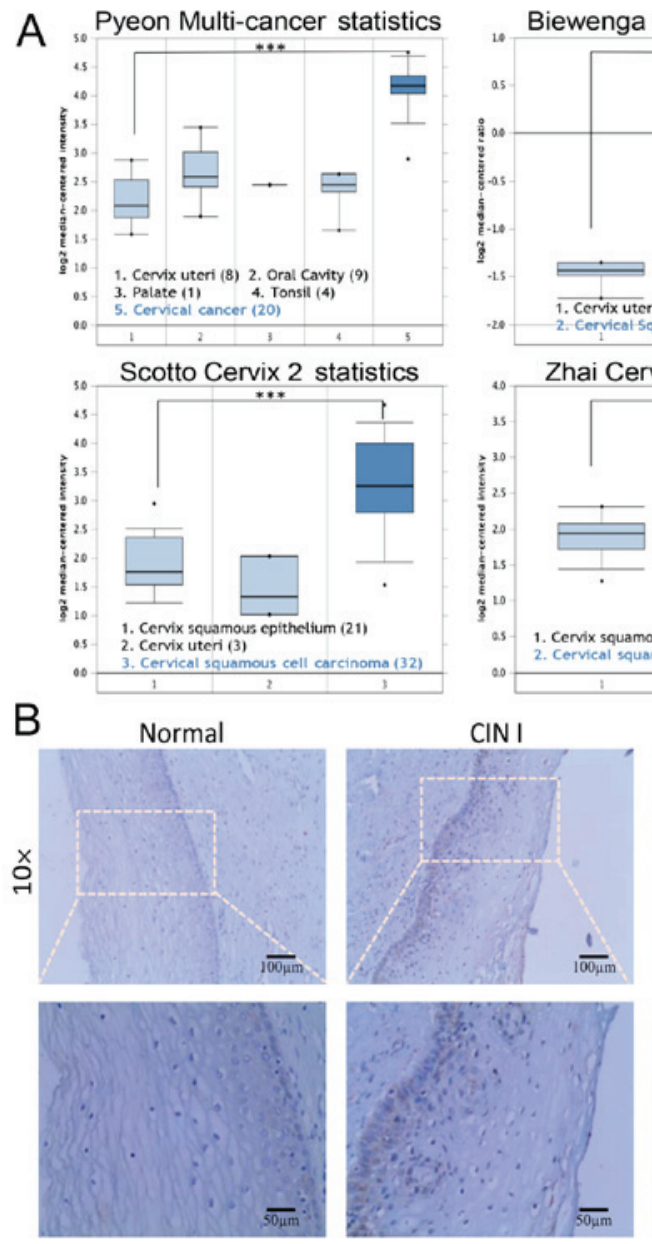

Biewenga Cervix statistics
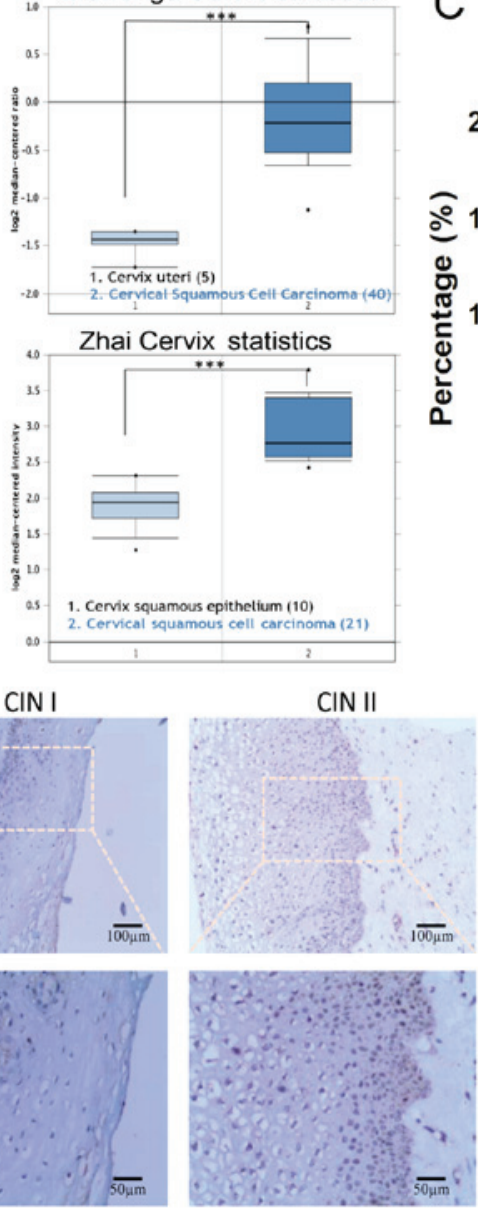

C

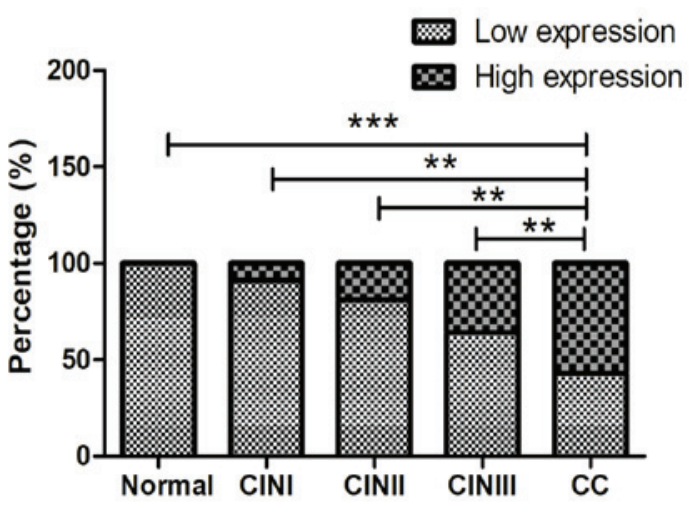

CIN III
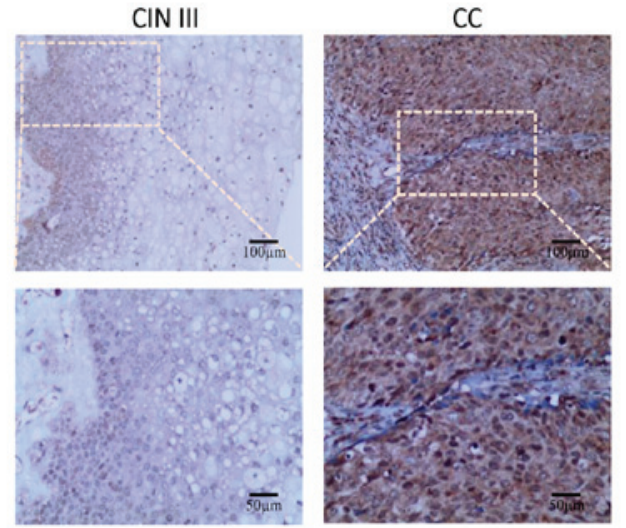

Figure 1. GMPS expression gradually increases from normal cervical to CIN to CC tissues. (A) GMPS was differentially expressed in the human CC expression profile database. By performing bioinformatics analysis of four datasets, it was found that the expression level of GMPS mRNA in CC tissues was significantly higher compared with that in corresponding normal cervical tissues. (B) GMPS expression in CIN and CC. (C) Proportion of high GMPS expression gradually increased with the progress of CC. ${ }^{* * *} \mathrm{P}<0.005,{ }^{* * *} \mathrm{P}<0.001$. CC, cervical cancer; GMPS, guanosine monophosphate synthase; CIN, cervical intraepithelial neoplasia.

GMPS expression in CC tissues is significantly higher compared with that in adjacent tissues. IHC results revealed that, in 32 cases of paired cancer and adjacent tissues, the expression rate of GMPS in cancer tissues was significantly higher compared with that in adjacent tissues. In 10 cases of cervical adenocarcinoma tissues, the high expression rate of GMPS was $50.00 \%(5 / 10)$ in adenocarcinoma tissue. There were 22 cases of cervical squamous cell carcinoma. The high expression rate of GMPS was 59.09\% (13/22) in squamous cell carcinoma tissues, while GMPS expression was not detected in adjacent tissues (Fig. 3A and B). RT-qPCR analysis was used to detect mRNA in 32 cases. The results indicated that the mean expression level of GMPS mRNA in CC tissues was significantly higher compared with that in matched para-cancerous tissues (Fig. 3C).

Association between abnormal expression of GMPS and clinicopathological characteristics. A total of $129 \mathrm{CC}$ tissue specimens were collected. Among them, the high expression rate of GMPS was 70.93\% (61/86) in patients with low-to-medium differentiation of cancer cells, and $30.23 \%(13 / 43)$ in patients with high differentiation of cancer cells. The results demonstrated that, compared with the high differentiation of cancer cells, the expression rate of GMPS was increased in the group with low-to- medium differentiation of cancer cells (Table II; Fig. 4A).

In total, 66 patients had $\mathrm{CC}$ stage Ib. According to postoperative pathology, 28 patients had deep myometrial invasion (tumor invasion of $>1 / 2$ the thickness of the myometrium), and 38 patients had superficial myometrial invasion (myometrium invasion $\leq 1 / 2$ of the total thickness). The findings indicated that, for stage Ib disease, the high expression rate of GMPS was increased in patients with tumors invading deep into the myometrium compared with those with superficial myometrial invasion (Table II; Fig. 4B).

GMPS expression in CC cell lines. Western blotting and RT-qPCR analysis were performed to evaluate the expression of GMPS in the four CC cell lines ( $\mathrm{SiHa}, \mathrm{HeLa}, \mathrm{C} 33 \mathrm{~A}$ and CaSki; Fig. 4C). GMPS was variably expressed in the four CC cell lines. GMPS protein and mRNA expression levels were markedly higher in $\mathrm{SiHa}$ and HeLa cells in comparison with C33A and CaSki cells (Fig. 4D and E).

Effect of GMPS knockdown on the proliferation and colony formation of CC cells. HeLa, SiHa, C33A and CaSki cells were transfected with Ctrl siRNA, siRNA\#1 and siRNA\#2. The results suggested that, compared with the Ctrl group, 

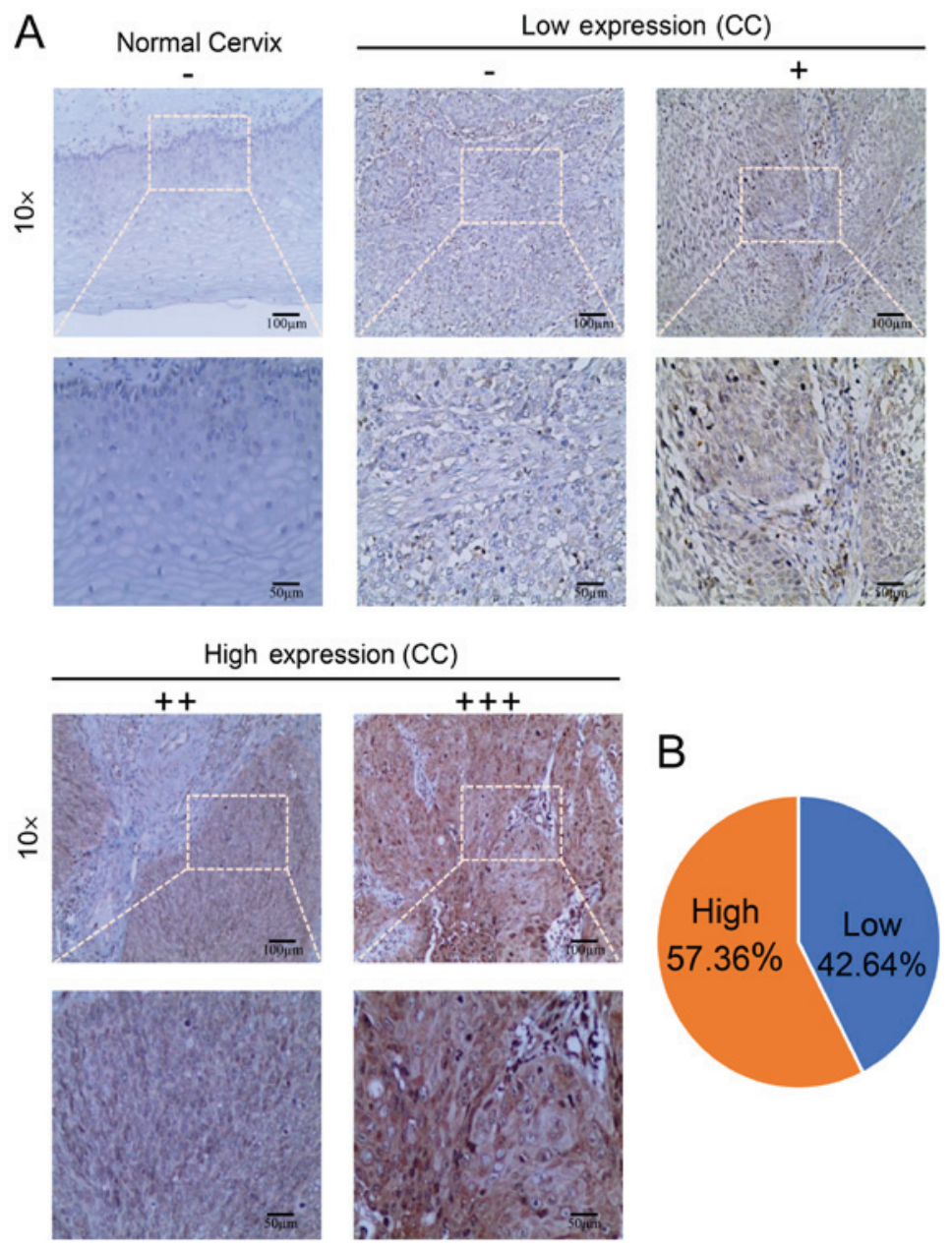

Figure 2. GMPS is expressed at a higher level in CC. (A) Immunohistochemistry results were interpreted by combining the staining intensity of positive reaction cells and the staining area (0-12 scores). The intensity of cell staining could be divided into negative ( 0 scores), mild positive ( 1 score), medium positive ( 2 scores) and strong positive ( 3 scores). The number of positive cells was <5\% ( 0 scores), $5-25 \%$ ( 1 score), 26-50\% ( 2 scores), $51-75 \%$ ( 3 scores) or $>75 \%$ ( 4 scores). The total score was the product of the staining intensity plus the stained area score. The scores 0-7 were deemed as low expression of GMPS, and scores 8-12 were deemed as high expression of GMPS. (B) The high expression rate of GMPS in CC was 57.36\%. CC, cervical cancer; GMPS, guanosine monophosphate synthase.

the cells in the GMPS siRNA knockdown group grew slowly at 0-5 days (Fig. 5A-C). The CC cells HeLa and SiHa were transfected with Ctrl siRNA, siRNA\#1, and siRNA\#1 combined with cisplatin. The results of the clone formation experiments indicated that GMPS knockdown could significantly decrease the colony-forming ability of the two CC cell lines, the group of siRNA\#1 combined with cisplatin was the most obviously decreased compared with the Ctrl siRNA group (Fig. 6A and B).

Effect of GMPS knockdown on the senescence and apoptosis of CC cells. HeLa and SiHa cells were transfected with Ctrl siRNA and siRNA\#1. The senescence of the cells in each group was observed, and it was found that GMPS knockdown could induce the senescence of HeLa and SiHa cells (Fig. 7A).

HeLa, SiHa, C33A and CaSki cells were transfected with Ctrl siRNA, siRNA\#1 and siRNA\#2. After $72 \mathrm{~h}$ of transfection, cells were detected via flow cytometry to analyze the effects of GMPS knockdown on CC cell apoptosis. Transfection with GMPS siRNA specifically knocked down the expression of GMPS in CC cells. Flow cytometry experiments demonstrated that knockdown of GMPS could increase the proportion of apoptotic cells (Fig. 7B and C). These findings indicated that
GMPS knockdown facilitated apoptosis, and that GMPS may enhance the malignant phenotype of tumors via the apoptotic pathway.

Knockdown of GMPS plays a tumor-suppressive role in CC. In the animal experiments, female nude mice were subcutaneously inoculated with HeLa (low GMPS expressing cell strain) cells transfected with short hairpin RNA (sh)-GMPS and HeLa sh-NC cells. The experimental results demonstrated that the tumor growth rate of the sh-GMPS group was significantly slower compared with that of the HeLa sh-NC group (Fig. 8A-C). GMPS was highly expressed in tumors of the sh-NC group, but its expression was low in tumors of the sh-GMPS group (Fig. 8D). Therefore, it was suggested that knockdown of GMPS exerted a tumor-suppressive effect on CC. In summary, knockdown of GMPS could suppress cancer growth rate in vitro and in vivo.

GMPS mediates the aging and apoptosis of CC cells via the Stat3/P53 pathway. HeLa and C33A cells were transfected with Ctrl siRNA, siRNA\#1, siRNA\#2 and siRNA\#3. Western blotting results indicated that, compared with the control group, Stat 3 and p-Stat 3 protein expression levels were markedly 

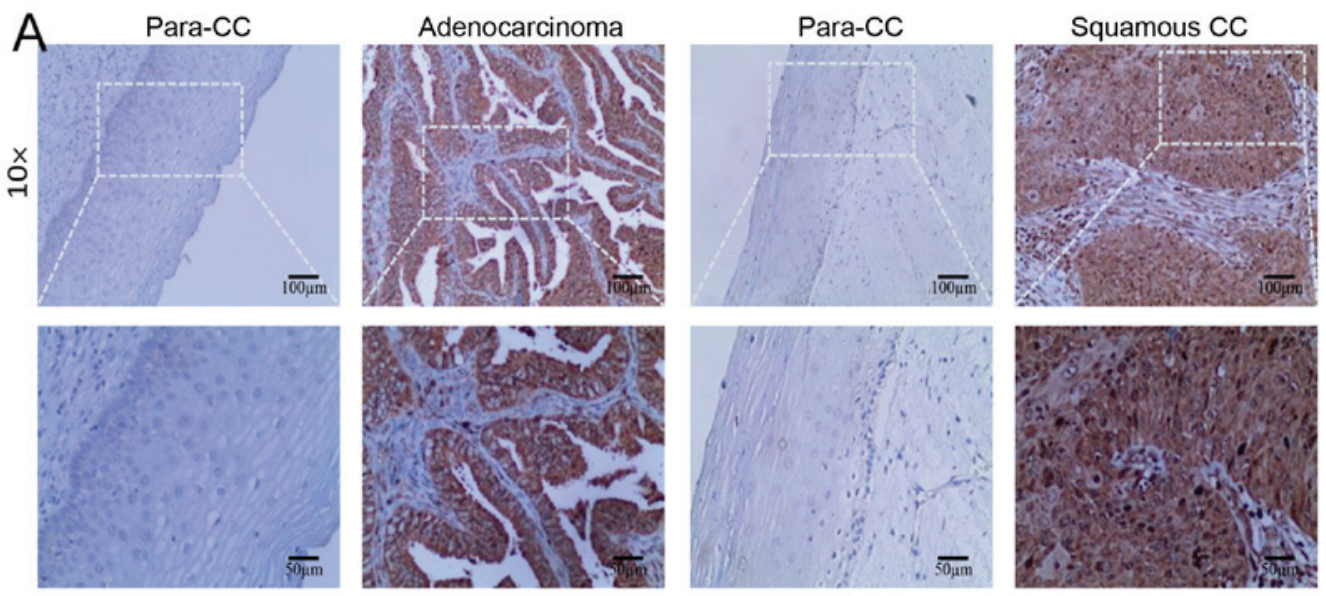

B

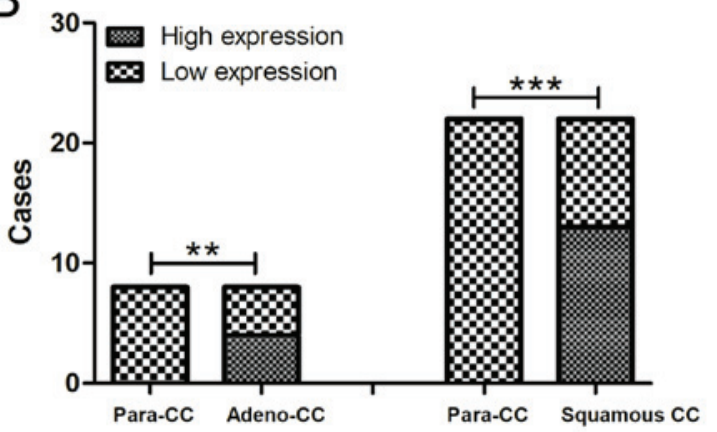

C

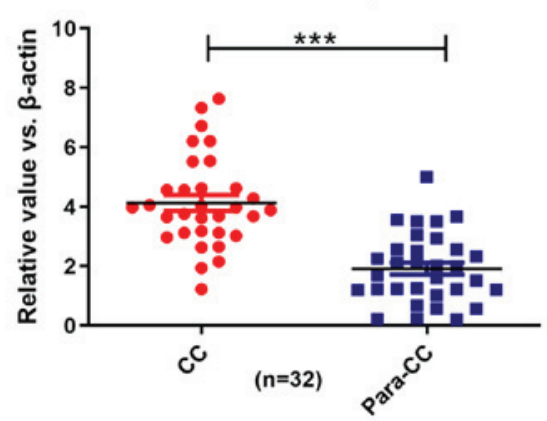

Figure 3. Expression levels of GMPS in CC is significantly higher than that in adjacent tissues. (A) Immunohistochemistry findings of cervical squamous cell carcinoma vs. adjacent cancerous tissues, and cervical adenocarcinoma vs. adjacent cancerous tissues. (B) Immunohistochemistry results demonstrated that the positive expression of GMPS in cancer tissues was significantly higher compared with that in adjacent tissues. (C) In 32 cases of cancer and adjacent tissues, reverse transcription-quantitative PCR results identified that the average expression level of GMPS mRNA in CC tissues was significantly higher compared with that in matched adjacent cancer tissues. ${ }^{* *} \mathrm{P}<0.005,{ }^{* * *} \mathrm{P}<0.001$. GMPS, guanosine monophosphate synthase; $\mathrm{CC}$, cervical cancer.
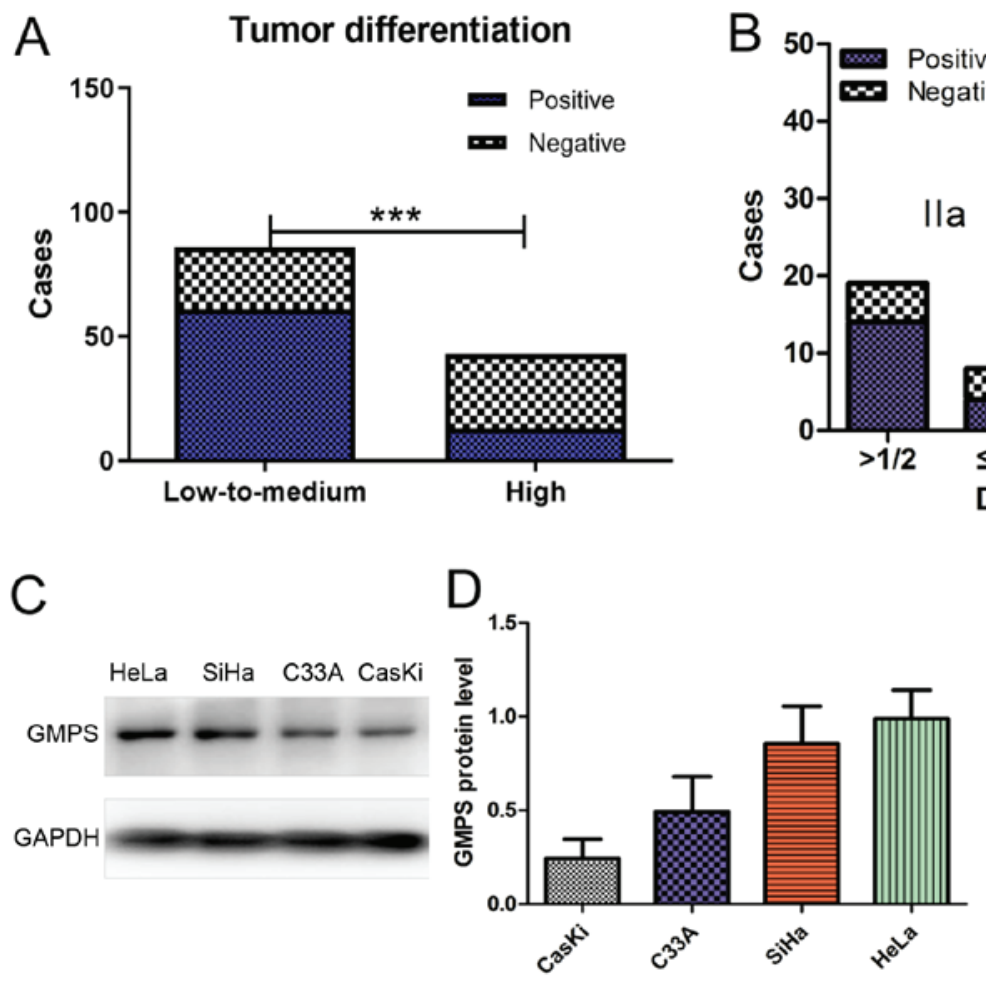
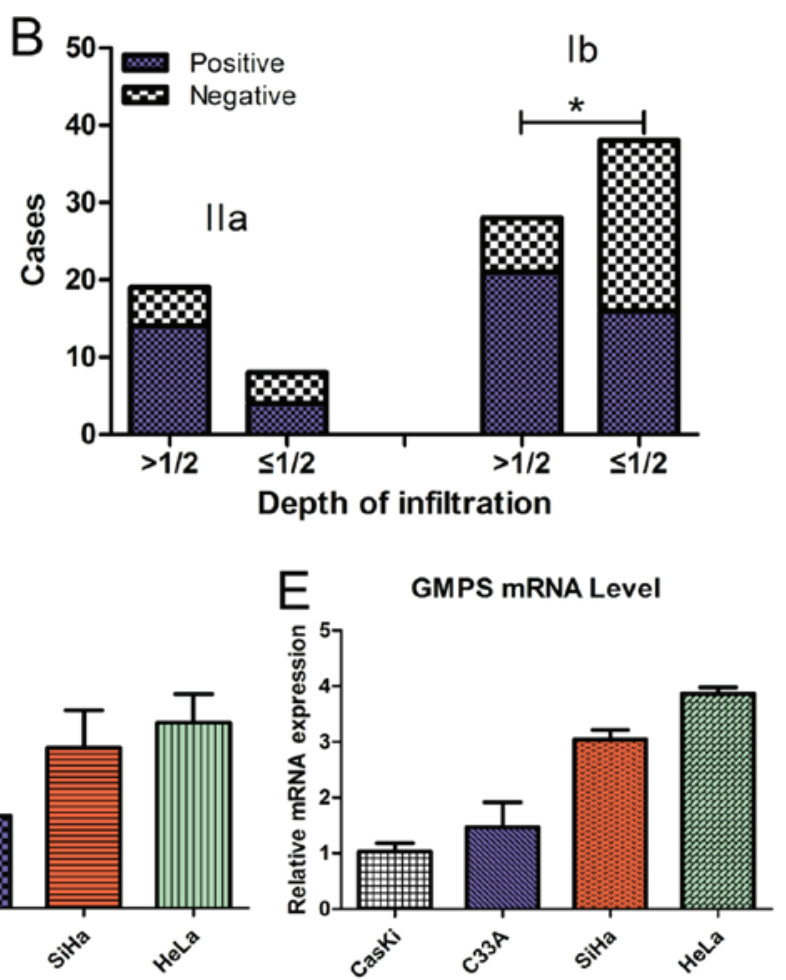

Figure 4. Association between abnormal expression of GMPS and clinicopathological characteristics. (A) Compared with highly differentiated CC, the expression rate of GMPS was higher in patients with low-to-medium differentiation of CC. (B) In stage Ib, compared with that in tumors with superficial muscle invasion, the high expression rate of GMPS was increased in tumor invasion of deep muscle. (C-E) GMPS was expressed in all four CC cell lines SiHa, HeLa, C33A and CaSki, especially in HeLa and SiHa cells. ${ }^{*} \mathrm{P}<0.05,{ }^{* * * *} \mathrm{P}<0.001$. CC, cervical cancer; GMPS, guanosine monophosphate synthase. 

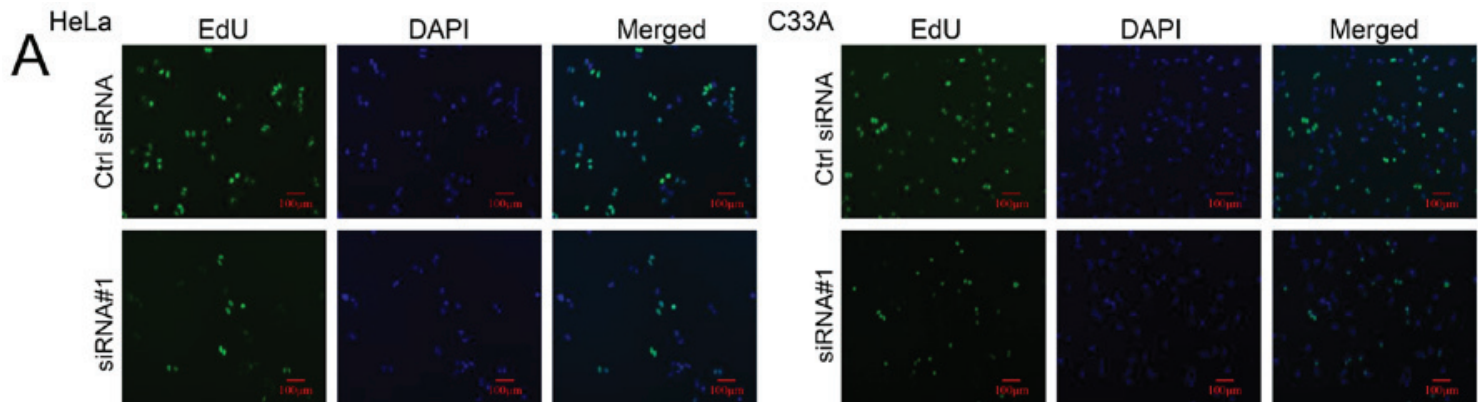

$\mathrm{SiHa}$
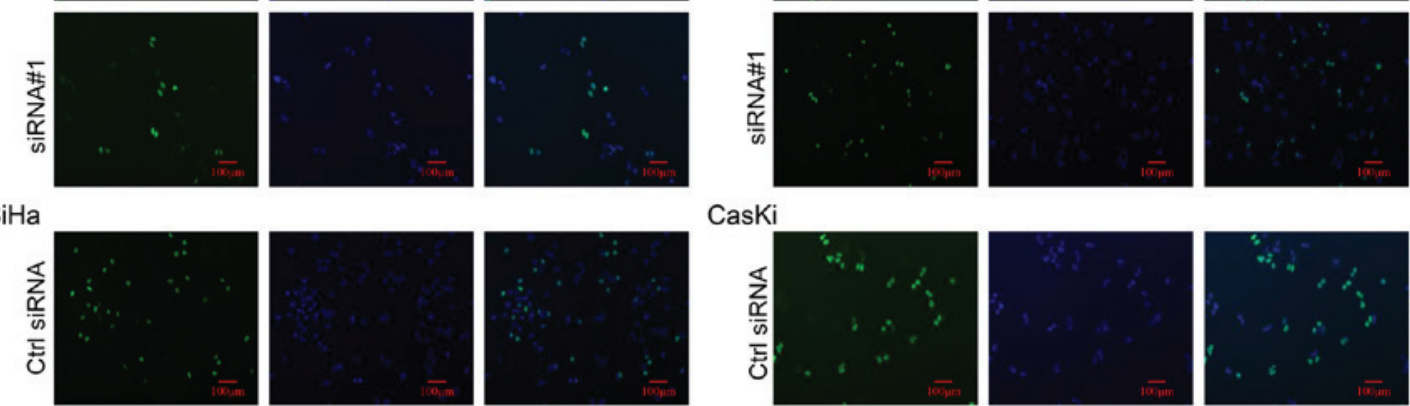

CasKi
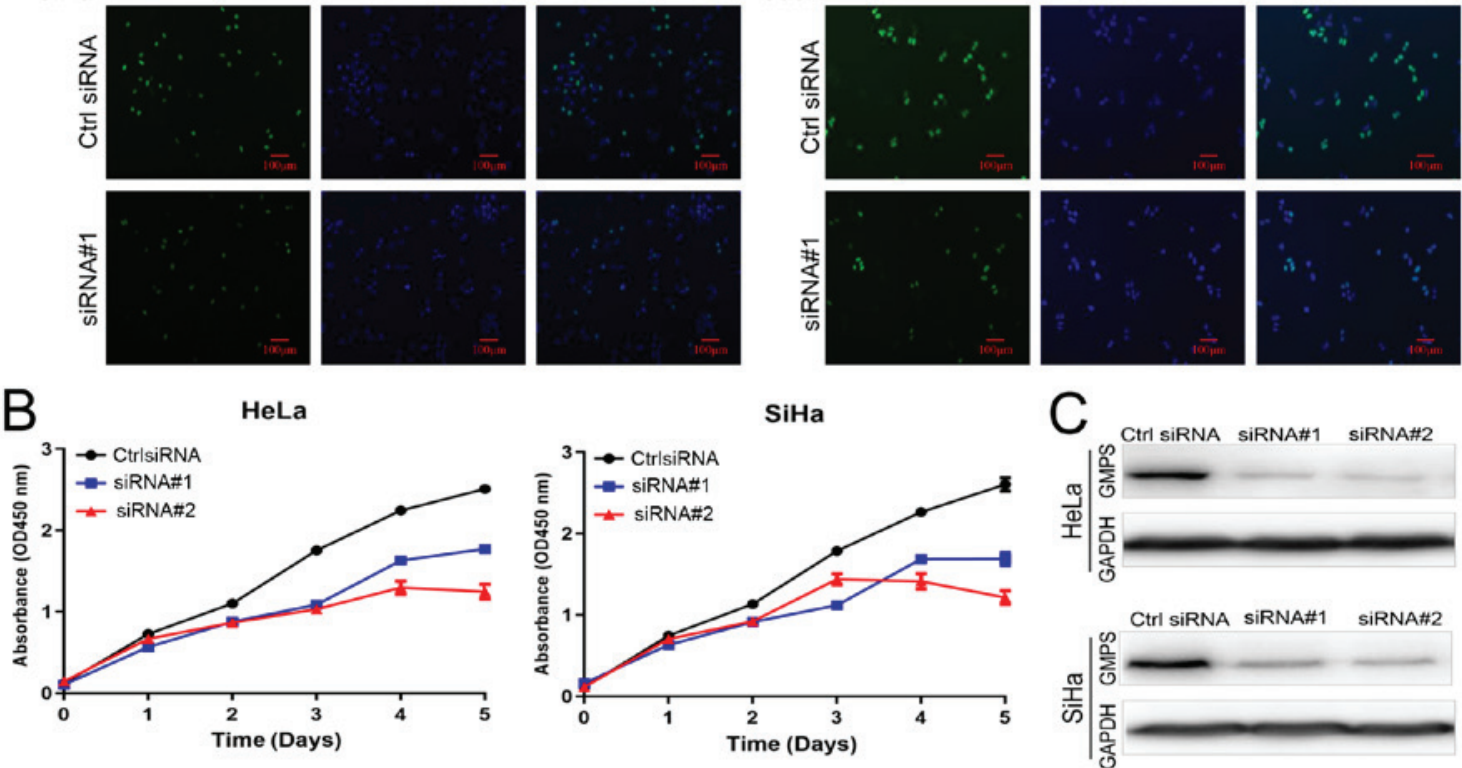

C

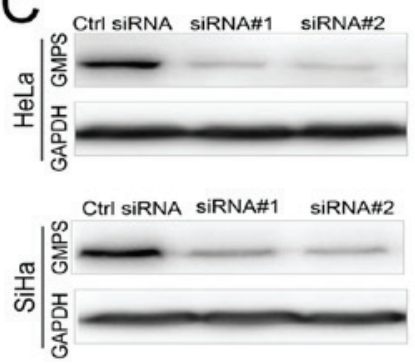

C33A

CasKi
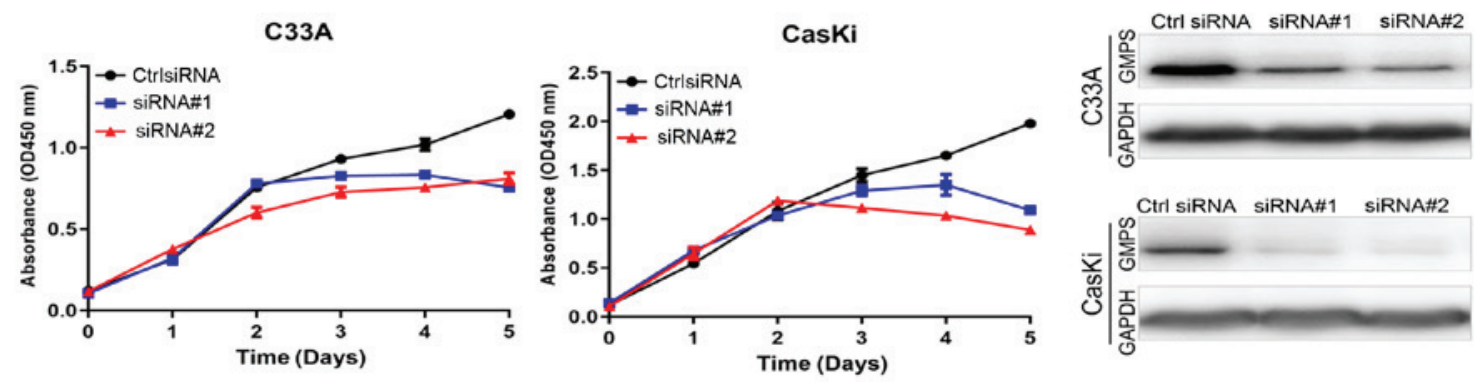

Figure 5. Effect of GMPS knockdown on the proliferation of CC cells. (A) 5-Ethynyl-2'-deoxyuridine and (B) Cell Counting Kit-8 assays were used to detect the proliferation of CC cells ( $\mathrm{SiHa}, \mathrm{HeLa}, \mathrm{C} 33 \mathrm{~A}$ and CaSki). The results demonstrated that, compared with the control group, cells in the GMPS siRNA knockdown group grew slowly. (C) In four CC cell lines, the expression of GMPS in the siRNA knockdown group was notably lower than that in the control group. CC, cervical cancer; GMPS, guanosine monophosphate synthase; siRNA, small inferring RNA; Ctrl, control.

decreased in the GMPS siRNA knockdown group. Moreover, the expression levels of the apoptotic protein P53 and p-P53 were increased (Fig. 9B). These findings were also confirmed in immunofluorescence experiments (Fig. 9A).

HeLa cells were transfected with Ctrl siRNA and siRNA\#1, and the cells were treated with or without cisplatin. Western blotting was used to detect Stat 3 and P53 protein expression levels. The protein expression levels of Stat 3 and p-Stat 3 in the siRNA\#1 + cisplatin treatment group were notably lower compared with those in the other groups. Furthermore, the protein expression levels of P53 and p-P53 were notably higher in the transfected and cisplatin-treated cells compared with those in the other groups (Fig. 9C).

In the animal experiments, the western blotting results demonstrated that, compared with the control group, the expression levels of P53 and p-P53 were upregulated in the sh-GMPS group, while the expression levels of Stat 3 and p-Stat3 were downregulated (Fig. 8E).

The results indicated that GMPS may participate in the regulation of CC cell senescence and apoptosis via the Stat3/P53 pathway.

\section{Discussion}

GMPS is a classic biosynthetic enzyme that promotes cell proliferation and DNA replication, most of the existing research on GMPS has been performed in bacteria and insects, it has been reported that GMPS is involved in chromatin and gene regulation $(8,12,22)$. A previous study revealed that GMPS metabolism serves an important role in controlling 


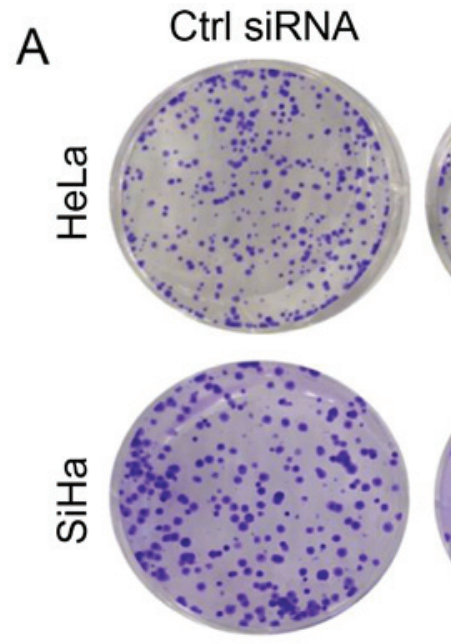

B

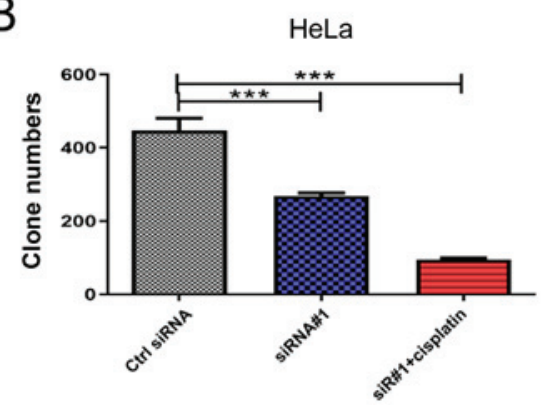

SiRNA\#1
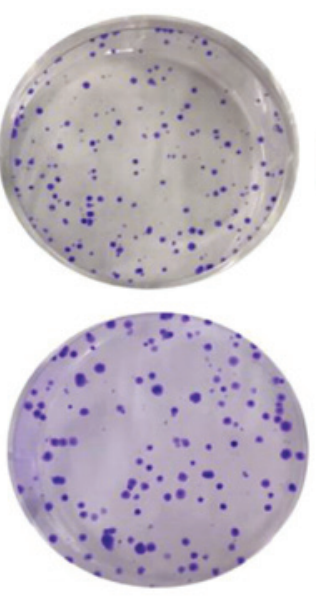

siR\#1+cisplatin
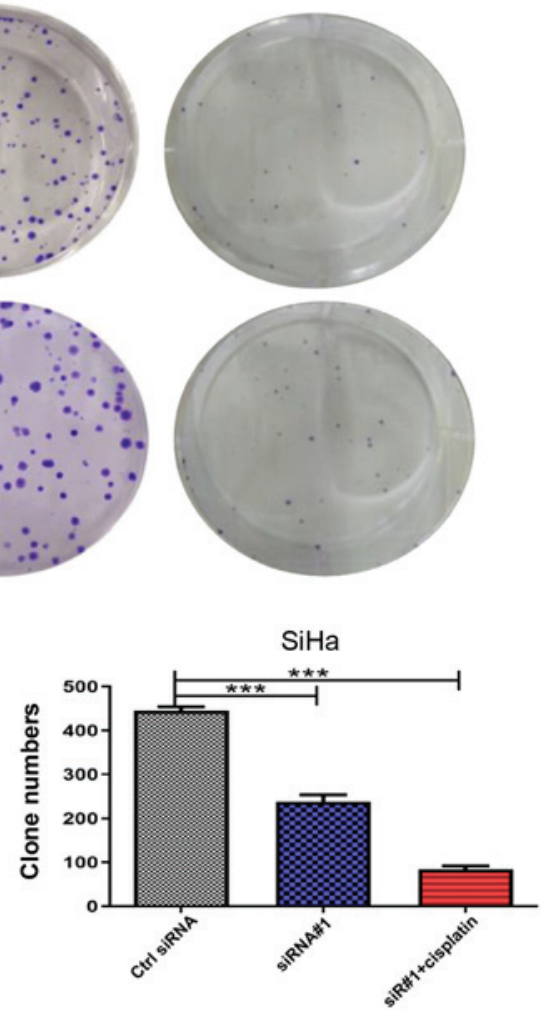

Figure 6. Effect of GMPS knockdown on the colony formation of CC cells. (A and B) HeLa and SiHa cells were transfected with Ctrl siRNA, siRNA\#1 and siRNA\#1 combined with cisplatin $(3 \mu \mathrm{g} / \mathrm{ml})$. The results demonstrated that GMPS knockdown could inhibit the clone formation ability in CC cells. ${ }^{* * *} \mathrm{P}<0.001$. CC, cervical cancer; GMPS, guanosine monophosphate synthase; siRNA, small inferring RNA; Ctrl, control.

the invasion and tumorigenicity of human melanoma cells. Furthermore, GMPS is associated with the degree of malignancy of tumors and is expected to become a novel target for anticancer therapy (14). The present study demonstrated that GMPS expression was upregulated at the mRNA and protein levels in four human CC cell lines. Moreover, GMPS was highly expressed in CC, with an expression rate of $57.36 \%$ in clinical specimens. However, in normal cervical and para-cancerous tissue, its expression was lower. The expression rate of GMPS was consecutively increased from normal cervical, to CIN I, CIN II, CIN III and CC tissues. Therefore, the present results suggested that GMPS may be involved in the progression of CC.

GMPS may participate in DNA replication, cell proliferation and abnormal cell division $(12,23)$. Thus, this multi-function enzyme may facilitate the development of novel therapeutic strategies in cancer and other diseases. Examination of clinical specimens of metastatic melanoma revealed that GMPS and guanosine monophosphate reductase were not associated the disease outcome, but were associated with cancer aggressiveness $(8,23)$. The present study indicated that, among the 129 patients with $\mathrm{CC}$, the expression rate of GMPS was higher in patients with low-to-medium differentiation of cancer cells compared with those with high cancer cell differentiation. Among the 66 patients with $\mathrm{CC}$ stage Ib, the expression rate of GMPS was higher in patients with tumor invasion of the deep muscularis layer of the myometrium. These results suggested that GMPS may be associated with the biological behavior of CC.
Apoptosis refers to the process of programmed cell death. Dysregulation of the apoptotic mechanism is a sign of cancer development. Apoptosis is associated with not only the occurrence and development of cancer, but also the treatment resistance of cancer $(24,25)$. The mechanism of apoptosis is complex and involves multiple signaling pathways. In general, regulating the balance between pro-apoptotic and anti-apoptotic proteins is a key factor in determining whether cells are apoptotic (26). Targeting molecules involved in apoptosis resistance is an effective treatment strategy for cancer (27-29). After knocking down GMPS using siRNA, the present study examined CC cell proliferation, colony-forming ability, senescence and apoptosis. The results demonstrated that knockdown of GMPS could significantly inhibit the proliferation and colony-forming abilities of CC cells, as well as promote cell aging and apoptosis. The animal experimental results showed that the tumor growth rate of the sh-GMPS group was significantly slower than that of the HeLa sh-NC group. These findings indicated that GMPS may inhibit the senescence and apoptosis of CC cells; however, the exact underlying mechanisms remain unknown.

Both Stat 3 and P53 are important regulators of cell proliferation and survival. These serve an important role in the stability and differentiation of cells, as well as participate in the carcinogenesis of numerous types of cells (30-32). Stat3 is activated in multiple types of human solid tumors and hematological malignancies, and it has been suggested that Stat3 may provide novel molecular targets for tumor treatments $(33,34)$. As a cytoplasmic transcription factor, nuclear 

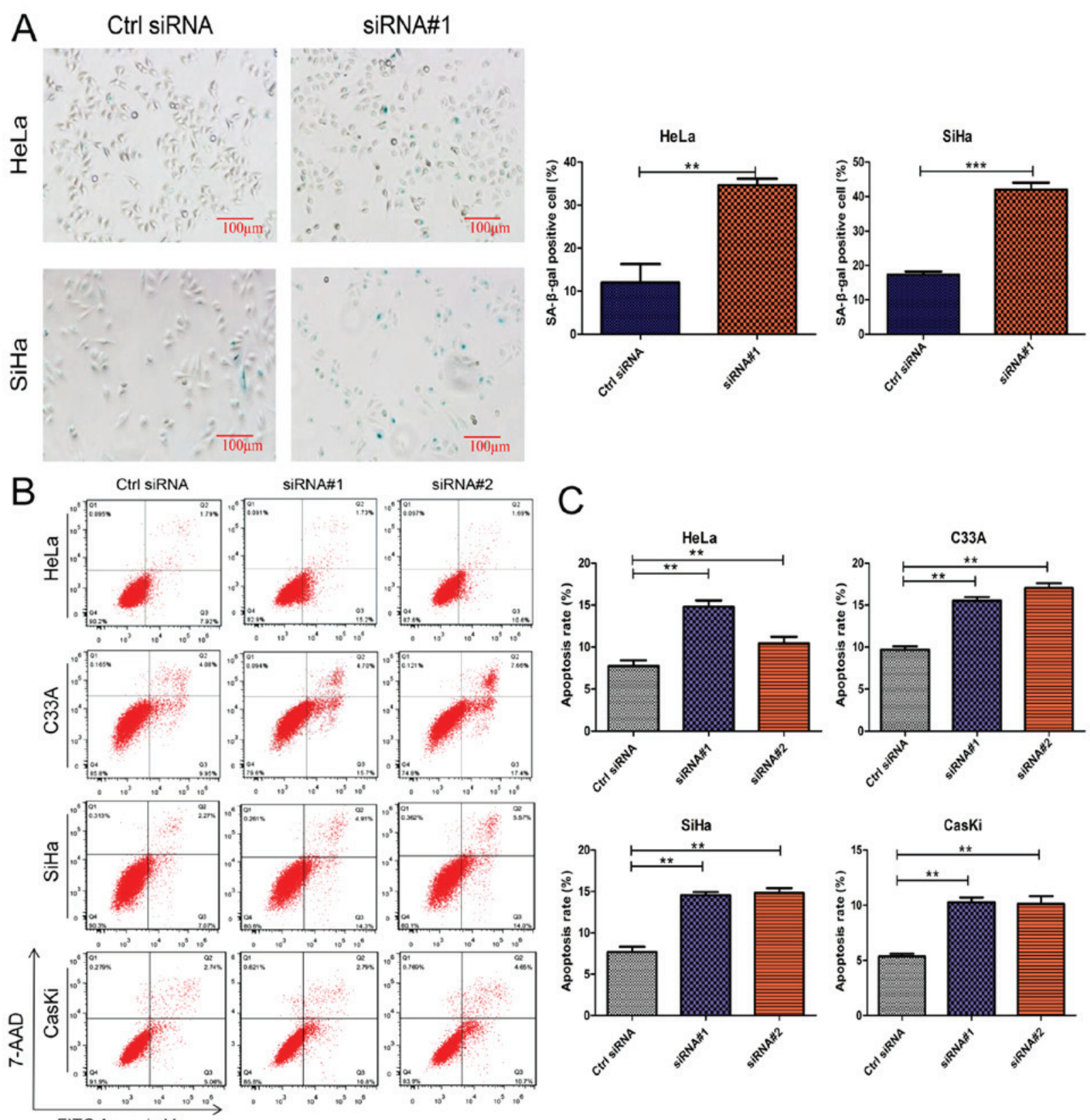

FITC Annexin V

Figure 7. Effect of GMPS knockdown on the senescence and apoptosis of CC cells. (A) GMPS knockdown could induce the aging of CC HeLa and SiHa cells. (B and C) Transfection of GMPS siRNA specifically knocked down GMPS expression in CC cells, and flow cytometry results indicated that this increased the proportion of apoptotic cells. ${ }^{* *} \mathrm{P}<0.005,{ }^{* * *} \mathrm{P}<0.001$. GMPS, guanosine monophosphate synthase; siRNA, small inferring RNA; CC, cervical cancer; Ctrl, control.

transport of Stat3 requires phosphorylation, and Stat3 is activated primarily by phosphorylation of the conserved tyrosine Tyr705 residue $(32,35)$. Since the early seminal work in the preclinical and clinical development of cisplatin, numerous analogues have been synthesized and tested for properties that may enhance their therapeutic index (36). The present study used siRNA to knock down GMPS, and CC cells were simultaneously treated with cisplatin. Compared with the control group, the expression levels of Stat 3 and p-Stat 3 in the GMPS siRNA knockdown group were decreased. P53 is a human tumor suppressor protein that serves a vital role in cell cycle control and apoptosis $(37,38)$. Previous studies have shown that Stat 3 inhibition could activate $\mathrm{p} 53$ expression in human cancer cells and induce p53-mediated tumor cell apoptosis (39). The present study demonstrated that, after knocking down GMPS, both Stat 3 and p-Stat 3 expression levels were decreased, which was accompanied by increased P53 and p-P53 expression levels, resulting in the induction of senescence and apoptosis in CC cells. These same changes were observed in the animal experiments. Based on these findings, it was suggested that overexpression of GMPS may inhibit the senescence and apoptosis of CC cells via the Stat3/P53 molecular pathway.

In conclusion, the present study demonstrated that GMPS was highly expressed in CC, and was associated with tumor differentiation and depth of invasion. It was also suggested that GMPS may be implicated in the processes of CC cell proliferation, colony formation, aging and apoptosis. Furthermore, GMPS may inhibit the senescence and apoptosis of CC cells via the Stat3/P53 molecular pathway. Thus, a novel therapeutic target may be developed based on GMPS for the treatment of CC. 

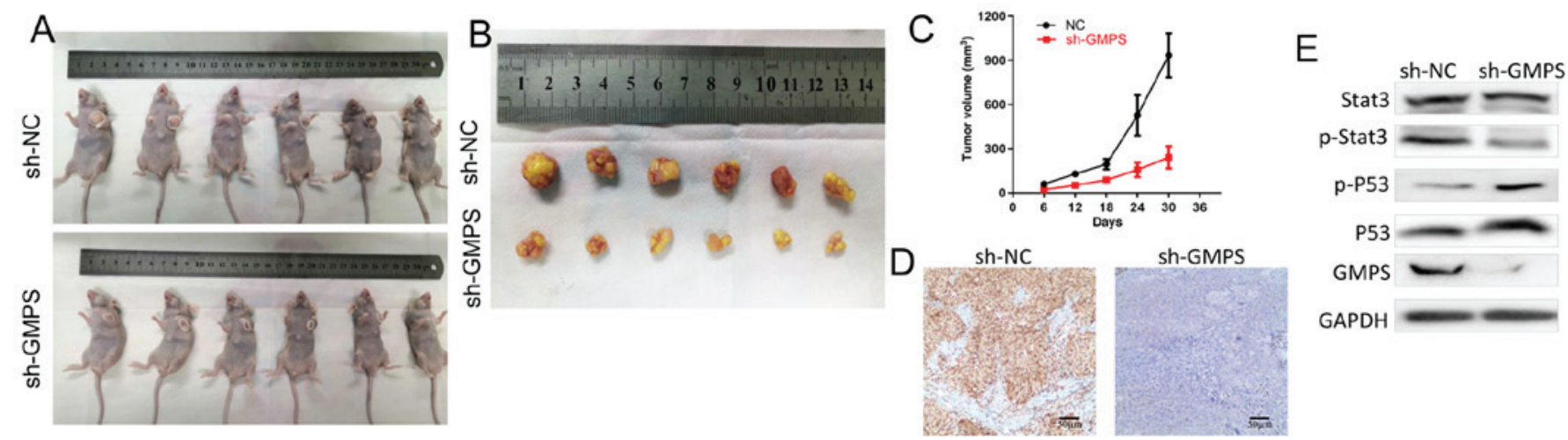

Figure 8. Knockdown of GMPS plays a tumor-suppressive role in cervical cancer. (A) Female nude mice (BALB/c nude mice) were injected subcutaneously with HeLa control cells (sh-NC) (upper panel) and GMPS knockdown cells (sh-GMPS) (lower panel). (B) After 5 weeks of rearing, the tumors were removed and the tumor size and quality were compared between the two groups. (C) Tumor volumes and weights were significantly larger in the control group compared with those in the sh-GMPS group. (D) Immunohistochemistry identified the differential expression of GMPS in the two groups of tumors from the nude mice. (E) Expression levels of P53 and p-P53 were upregulated in the sh-GMPS group, and the expression levels of Stat3 and p-Stat 3 were downregulated in the sh-GMPS group. sh, short hairpin RNA; GMPS, guanosine monophosphate synthase; NC, negative control; p-, phosphorylated.
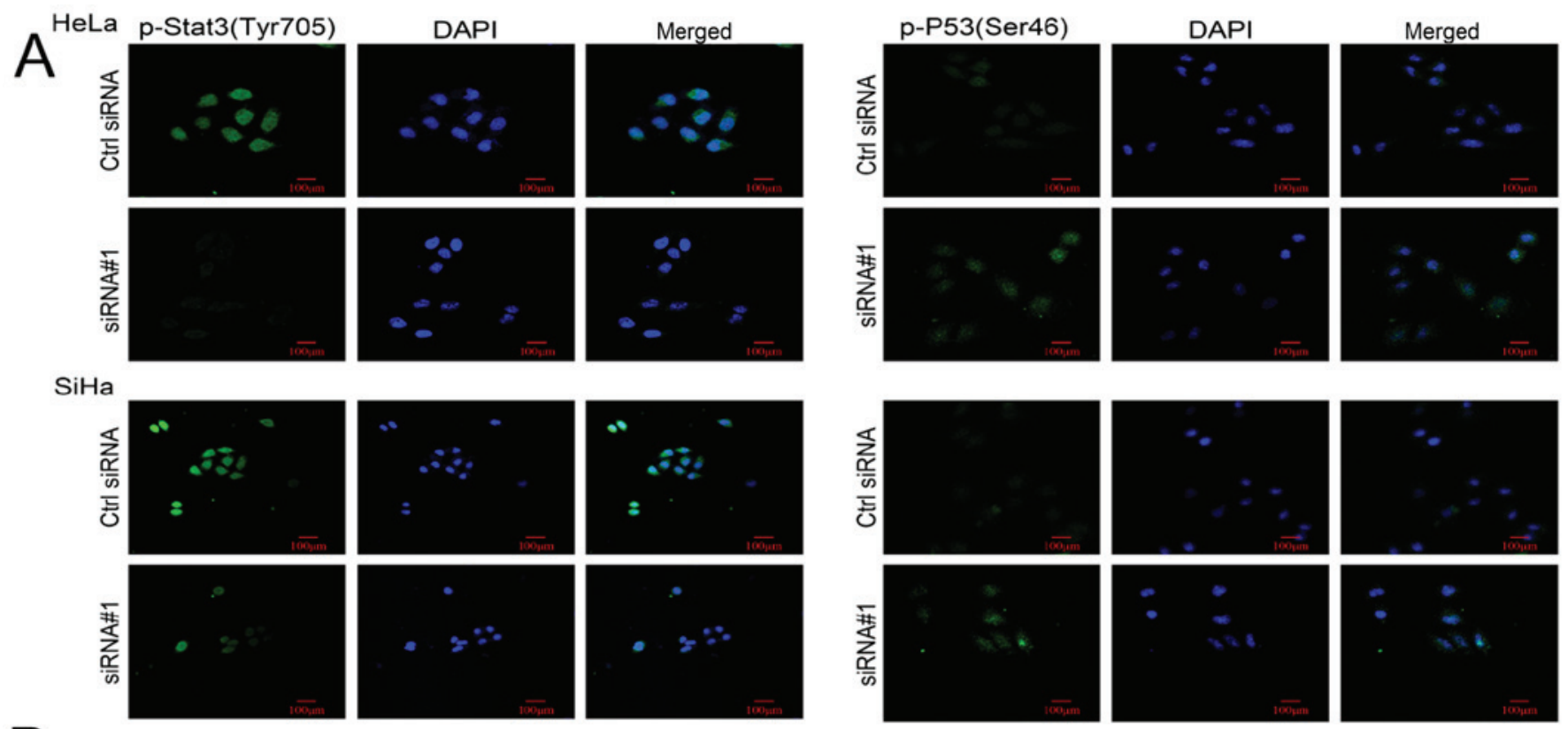

B

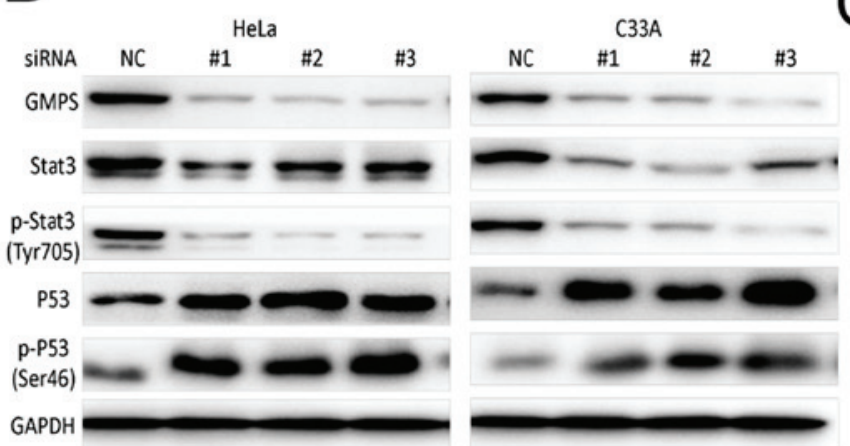

$\mathrm{C}_{\text {nut }}$

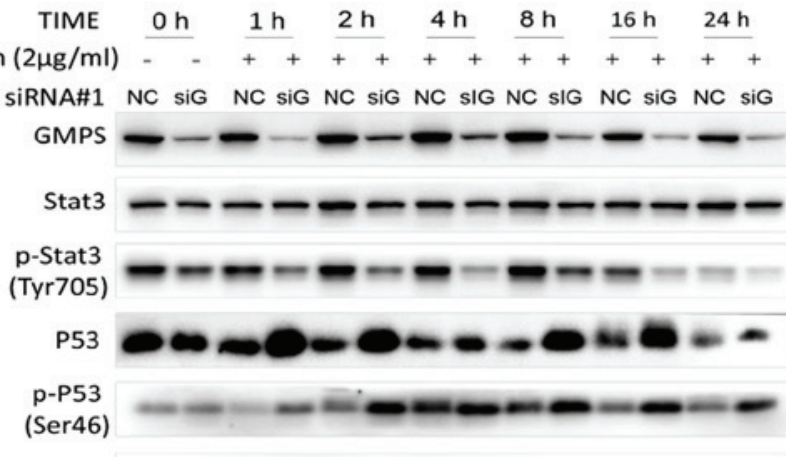

GAPDH $-0-0-0-0-0-0$

Figure 9. GMPS mediates the aging and apoptosis of cervical cancer cells via the Stat3/P53 pathway. (A) HeLa and SiHa cells were transfected with Ctrl siRNA and siRNA\#1. Immunofluorescence identified that p-Stat3 expression level was decreased in the GMPS siRNA knockdown group, compared with the control group. However, p-P53 expression level was increased. (B) HeLa and C33A cells were transfected with Ctrl siRNA, siRNA\#1, siRNA\#2 and siRNA\#3. Western blotting results demonstrated that Stat 3 and p-Stat3 protein expression levels were decreased, and those of P53 and p-P53 were increased. (C) HeLa cells were transfected with Ctrl siRNA and siRNA\#1, and then treated with cisplatin. Western blotting was conducted to detect Stat3 and P53 protein expression levels at different time points. The results suggested that the expression levels of Stat 3 and p-Stat 3 in GMPS siRNA and cisplatin intervention groups were notably lower compared with those in single cisplatin group and the control group. P53 and p-P53 expression levels were notably higher in GMPS siRNA and cisplatin intervention groups. GMPS, guanosine monophosphate synthase; NC, negative control; p-, phosphorylated; Ctrl, control; siRNA, small interfering RNA. 


\section{Acknowledgements}

Not applicable.

\section{Funding}

The present study was funded by the National Natural Science Foundation of China, (grant nos. 81672560, 81772773 and $81302275)$, the Project of Suzhou Minsheng Science and Technology (grant no. SYSD2019204) and the Project of Suzhou Science and Technology Development Plan (grant no. SLJ202006).

\section{Availability of data and materials}

The data generated and analyzed during the current study are available from the corresponding author on reasonable request. Public data and data repositories are referenced within the manuscript.

\section{Authors' contributions}

JW, YWu, YL, FS and YWa performed the research. YWu, YL and YWa analyzed the data. JW, YWu and YL wrote the paper. JZ and YC conceived and designed the study, and they have seen and can confirm the authenticity of the raw data. All authors read and approved the final manuscript.

\section{Ethics approval and consent to participate}

Informed consent was obtained from all patients, and the study was approved by the Ethics Committee of The First Affiliated Hospital of Soochow University (approval no. 2019LS083; Suzhou, China). All animal experiments were performed with the approval of the Ethics Committee of Soochow University (approval no. SUDA20201027A01).

\section{Patient consent for publication}

Not applicable.

\section{Competing interests}

The authors declare that they have no competing interests.

\section{References}

1. Melan K, Janky E, Macni J, Ulric-Gervaise S, Dorival MJ, Veronique-Baudin $\mathrm{J}$ and Joachim C: Epidemiology and survival of cervical cancer in the French West-Indies: Data from the Martinique Cancer Registry (2002-2011). Glob Health Action 10: 1337341, 2017

2. Bray F, Ferlay J, Soerjomataram I, Siegel RL, Torre LA and Jemal A: Global cancer statistics 2018: GLOBOCAN estimates of incidence and mortality worldwide for 36 cancers in 185 countries. CA Cancer J Clin 68: 394-424, 2018.

3. Vu M, Yu J, Awolude OA and Chuang L: Cervical cancer worldwide. Curr Probl Cancer 42: 457-465, 2018.

4. Arbyn M, Weiderpass E, Bruni L, de Sanjosé S, Saraiya M, Ferlay $\mathbf{J}$ and Bray F: Estimates of incidence and mortality of cervical cancer in 2018: A worldwide analysis. Lancet Glob Health 8: e191-e203, 2020.

5. Ferlay J, Steliarova-Foucher E, Lortet-Tieulent J, Rosso S, Coebergh JW, Comber H, Forman D and Bray F: Cancer incidence and mortality patterns in Europe: Estimates for 40 countries in 2012. Eur J Cancer 49: 1374-1403, 2013.
6. Cohen PA, Jhingran A, Oaknin A and Denny L: Cervical cancer. Lancet 393: 169-182, 2019.

7. Li H, Wu X and Cheng X: Advances in diagnosis and treatment of metastatic cervical cancer. J Gynecol Oncol 27: e43, 2016.

8. Reddy BA, van der Knaap JA, Bot AG, Mohd-Sarip A, Dekkers DH, Timmermans MA, Martens JW, Demmers JA and Verrijzer CP: Nucleotide biosynthetic enzyme GMP synthase is a TRIM21-controlled relay of p53 stabilization. Mol Cell 53: 458-470, 2014.

9. van der Knaap JA, Kozhevnikova E, Langenberg K, Moshkin YM and Verrijzer CP: Biosynthetic enzyme GMP synthetase cooperates with ubiquitin-specific protease 7 in transcriptional regulation of ecdysteroid target genes. Mol Cell Biol 30: 736-744, 2010.

10. van der Knaap JA, Kumar BR, Moshkin YM, Langenberg K, Krijgsveld J, Heck AJ, Karch F and Verrijzer CP: GMP synthetase stimulates histone $\mathrm{H} 2 \mathrm{~B}$ deubiquitylation by the epigenetic silencer USP7. Mol Cell 17: 695-707, 2005.

11. Wang P, Zhang Z, Ma Y, Lu J, Zhao H, Wang S, Tan J and Li B: Prognostic values of GMPS, PR, CD40, and p21 in ovarian cancer. PeerJ 7: e6301, 2019.

12. Zhang P, Li X, He Q, Zhang L, Song K, Yang X, He Q, Wang Y, Hong X, Ma J, et al: TRIM21-SERPINB5 aids GMPS repression to protect nasopharyngeal carcinoma cells from radiation-induced apoptosis. J Biomed Sci 27: 30, 2020.

13. Cerami E, Gao J, Dogrusoz U, Gross BE, Sumer SO, Aksoy BA, Jacobsen A, Byrne CJ, Heuer ML, Larsson E, et al: The cBio cancer genomics portal: An open platform for exploring multidimensional cancer genomics data. Cancer Discov 2: 401-404, 2012.

14. Bianchi-Smiraglia A, Wawrzyniak JA, Bagati A, Marvin EK, Ackroyd J, Moparthy S, Bshara W, Fink EE, Foley CE, Morozevich GE, et al: Pharmacological targeting of guanosine monophosphate synthase suppresses melanoma cell invasion and tumorigenicity. Cell Death Differ 22: 1858-1864, 2015.

15. Pyeon D, Newton MA, Lambert PF, den Boon JA, Sengupta S, Marsit CJ, Woodworth CD, Connor JP, Haugen TH, Smith EM, et al: Fundamental differences in cell cycle deregulation in human papillomavirus-positive and human papillomavirus-negative head/neck and cervical cancers. Cancer Res 67: 4605-4619, 2007.

16. Biewenga P, Buist MR, Moerland PD, Ver Loren van Themaat E, van Kampen $\mathrm{AH}$, ten Kate FJ and Baas F: Gene expression in early stage cervical cancer. Gynecol Oncol 108: 520-526, 2008.

17. Scotto L, Narayan G, Nandula SV, Arias-Pulido H, Subramaniyam S, Schneider A, Kaufmann AM, Wright JD, Pothuri B, Mansukhani M, et al: Identification of copy number gain and overexpressed genes on chromosome arm 20q by an integrative genomic approach in cervical cancer: Potential role in progression. Genes Chromosomes Cancer 47: 755-765, 2008.

18. Zhai Y, Kuick R, Nan B, Ota I, Weiss SJ, Trimble CL, Fearon ER and Cho KR: Gene expression analysis of preinvasive and invasive cervical squamous cell carcinomas identifies HOXC10 as a key mediator of invasion. Cancer Res 67: 10163-10172, 2007.

19. Livak KJ and Schmittgen TD: Analysis of relative gene expression data using real-time quantitative PCR and the 2(-Delta Delta C(T)) method. Methods 25: 402-408, 2001.

20. National Research Council: Institute for Laboratory Animal Research: Guide for the Care and Use of Laboratory Animals. National Academies Press, Washington, DC, pp80-83, 1996.

21. FIGO staging for carcinoma of the vulva, cervix, and corpus uteri(the official organ of the International Federation of Gynaecology and Obstetrics). Int J Gynaecol Obstet 125: 97-98, 2014.

22. Kozhevnikova EN, van der Knaap JA, Pindyurin AV, Ozgur Z, van Ijcken WF, Moshkin YM and Verrijzer CP: Metabolic enzyme IMPDH is also a transcription factor regulated by cellular state. Mol Cell 47: 133-139, 2012.

23. Wawrzyniak JA, Bianchi-Smiraglia A, Bshara W, Mannava S, Ackroyd J, Bagati A, Omilian AR, Im M, Fedtsova N, Miecznikowski JC, et al: A purine nucleotide biosynthesis enzyme guanosine monophosphate reductase is a suppressor of melanoma invasion. Cell Rep 5: 493-507, 2013.

24. Fuchs Y and Steller H: Programmed cell death in animal development and disease. Cell 147: 742-758, 2011.

25. Pistritto G, Trisciuoglio D, Ceci C, Garufi A and D'Orazi G: Apoptosis as anticancer mechanism: Function and dysfunction of its modulators and targeted therapeutic strategies. Aging (Albany NY) 8: 603-619, 2016.

26. Wong RS: Apoptosis in cancer: From pathogenesis to treatment. J Exp Clin Cancer Res 30: 87, 2011. 
27. Baig S, Seevasant I, Mohamad J, Mukheem A, Huri HZ and Kamarul T: Potential of apoptotic pathway-targeted cancer therapeutic research: Where do we stand? Cell Death Dis 7: e2058, 2016.

28. Fulda S: Targeting apoptosis for anticancer therapy. Semin Cancer Biol 31: 84-88, 2015.

29. Giménez-Bonafé P, Tortosa A and Pérez-Tomás R: Overcoming drug resistance by enhancing apoptosis of tumor cells. Curr Cancer Drug Targets 9: 320-340, 2009.

30. Avalle L, Camporeale A, Camperi A and Poli V: STAT3 in cancer: A double edged sword. Cytokine 98: 42-50, 2017.

31. Banerjee K and Resat H: Constitutive activation of STAT3 in breast cancer cells: A review. Int J Cancer 138: 2570-2578, 2016.

32. Galoczova M, Coates P and Vojtesek B: STAT3, stem cells, cancer stem cells and p63. Cell Mol Biol Lett 23: 12, 2018.

33. Buettner R, Mora LB and Jove R: Activated STAT signaling in human tumors provides novel molecular targets for therapeutic intervention. Clin Cancer Res 8: 945-954, 2002.

34. Yu H and Jove R: The STATs of cancer--new molecular targets come of age. Nat Rev Cancer 4: 97-105, 2004.
35. Decker T and Kovarik P: Transcription factor activity of STAT proteins: Structural requirements and regulation by phosphorylation and interacting proteins. Cell Mol Life Sci 55: 1535-1546, 1999.

36. Dasari $\mathrm{S}$ and Tchounwou PB: Cisplatin in cancer therapy: Molecular mechanisms of action. Eur J Pharmacol 740: 364-378, 2014.

37. Chatterjee K, Das P, Chattopadhyay NR, Mal S and Choudhuri T: The interplay between Epstein-Bar virus (EBV) with the p53 and its homologs during EBV associated malignancies. Heliyon 5: e02624, 2019.

38. Sullivan KD, Galbraith MD, Andrysik Z and Espinosa JM: Mechanisms of transcriptional regulation by p53. Cell Death Differ 25: 133-143, 2018.

39. Niu G, Wright KL, Ma Y, Wright GM, Huang M, Irby R, Briggs J, Karras J, Cress WD, Pardoll D, et al: Role of Stat 3 in regulating p53 expression and function. Mol Cell Biol 25: 7432-7440, 2005.

(i) $(9)$ This work is licensed under a Creative Commons

c) Attribution-NonCommercial-NoDerivatives 4.0 International (CC BY-NC-ND 4.0) License. 